\title{
Obstetricians' and gynecologists' knowledge, education, and practices regarding chronic hepatitis B in pregnancy
}

\author{
Bolin Niua , Dina Halegoua-De Marziob, Jonathan M. Fenkel' ${ }^{b}$, Steven K. Herrine ${ }^{b}$
}

Thomas Jefferson University Hospital; Sidney Kimmel Medical College at Thomas Jefferson University, Philadelphia, PA, USA

\section{Abstract}

\section{Introduction}

Between 800,000 and 1.4 million people in the United States are infected with the hepatitis B virus (HBV) [1].

Department of Medicine, Division of Gastroenterology and Hepatology, ${ }^{a}$ Thomas Jefferson University Hospital (Bolin Niu); bSidney Kimmel Medical College at Thomas Jefferson University (Dina Halegoua-De Marzio, Jonathan M. Fenkel, Steven K. Herrine), Philadelphia, PA, USA

\section{Conflict of Interest: None}

Correspondence to: Dina Halegoua-De Marzio, MD, Division of Gastroenterology and Hepatology, Thomas Jefferson University Hospital, 480 Main, 132 South $10^{\text {th }}$ Street, Philadelphia, PA 19107, USA, e-mail: dina.halegoua-demarzio@jefferson.edu

Received 20 July 2017; accepted 31 August 2017; published online 30 September 2017

DOI: https://doi.org/10.20524/aog.2017.0196
$\mathrm{HBV}$ is a major risk factor for hepatocellular carcinoma, leading to $50 \%$ of cases worldwide. There is an estimated prevalence of $0.7-0.9 \%$ of chronic $\mathrm{HBV}$ among pregnant women in the US, with $>25,000$ neonates at risk for chronic infection annually $[2,3]$.

Obstetricians and gynecologists (OB-GYNs) perform a key role in the prevention of mother-to-child transmission (MTCT). To provide optimal care of pregnant women who are HBV carriers, OB-GYNs need appropriate knowledge, education, and practice in the management of these patients.

The Centers for Disease Control and Prevention and the American College of OB-GYNs (ACOG) have both published recommendations for screening for $\mathrm{HBV}$ among pregnant women [5], calling for hepatitis B surface antigen (HBsAg) as the initial serological testing for all pregnant women, followed by hepatitis B e-antigen (HBeAg), HBV DNA viral load, and alanine aminotransferase (ALT). If HBeAg is positive, $\mathrm{HBV}$ DNA $>20,000 \mathrm{IU} / \mathrm{mL}$, or ALT $\geq 19 \mathrm{IU} / \mathrm{L}$, then the 
patient should be referred to a specialist immediately during pregnancy.

The 2016 American Association for the Study of Liver Diseases (AASLD) guidelines suggest antiviral therapy to reduce the risk of perinatal transmission of hepatitis $B$ in pregnant women with an HBV DNA level $>200,000 \mathrm{IU} / \mathrm{mL}$ (>1 million copies $/ \mathrm{mL}$ ) [4]. The 2016 Society for MaternalFetal Medicine consensus recommends third-trimester HBV viral load testing and antiviral therapy over a greater range of viral load (HBV DNA > 1 million to 100 million copies $/ \mathrm{mL}$ ) compared to the AASLD recommendation.

The current survey aimed to determine the knowledge, education, and practices of OB-GYNs regarding HBV in pregnant women. In addition, we determined referral patterns and thresholds for OB-GYNs to treat patients with HBV.

\section{Materials and methods}

\section{Participants}

All program directors (PDs) from the 250 US OB-GYN residency programs were invited via e-mail to complete an 18 item online survey. E-mail addresses for PDs were obtained from the American Medical Association FREIDA web site. OB-GYN residents, contacted via e-mail by their PDs, were also invited to participate.

\section{Survey and administration}

An 18-item survey was sent to PDs to obtain demographic information and assess their knowledge, clinical practice, and residency program education with regard to pregnant women with chronic HBV. A slightly different 18 -item survey was written for trainees to obtain demographic information and assess knowledge, clinical practice, and comfort level when treating pregnant women with chronic HBV. The survey was first piloted at several programs and adjusted from feedback. Exemption status was obtained from Thomas Jefferson University's Institutional Review Board. Question responses included agree, disagree, or unsure. Many questions allowed for free-text comments. In January 2016, all participants were contacted via e-mail with a cover letter describing the study and a link to the Survey Monkey Website. Follow-up emails were sent at 4 and 8 weeks after the initial e-mail to encourage participation. Anonymized responses were stored in a database for analysis.

\section{Statistical analysis}

Descriptive statistics, including means for continuous variables and frequencies for categorical variables, were calculated. The chi-squared test for significance was employed.

\section{Results}

\section{Characteristics of responders}

A total of 323 participants from ACGME-accredited OBGYN residency programs across the US responded to the survey (Table 1). The respondents included both PDs $(n=51$, response rate of $21 \%)$ and residents $(n=272$, response rate of $11 \%)$. The responding resident cohort exhibited a diversity of experience, with equal distribution across postgraduate years (PGY) of training. Responding PDs came from varied practice settings, including university-based (62\%), community-based (32\%), and military-based (6\%).

\section{Practice patterns and peripartum management}

All PDs and $95.2 \%$ of residents reported screening for chronic HBV in pregnant patients on the first prenatal visit. Referral patterns showed that $66.7 \%$ of PDs and $65.5 \%$ of residents referred to a specialist regardless of viral load. A minority of respondents (19.6\% PD, $12.6 \%$ residents) knew that third-trimester antiviral therapy is recommended for women with high viral loads ( $>1$ million copies $/ \mathrm{mL}$ or $200,000 \mathrm{IU} / \mathrm{mL}$ ). Few respondents had prescribed antivirals for HBV (9.8\% PD, 6.0\% residents). Residents more commonly prescribed tenofovir (75\%) and less frequently lamivudine (16.7\%). In contrast, more PDs prescribed lamivudine (60\%) and fewer tenofovir (40\%). Furthermore, most PDs (98\%) and residents $(83.1 \%)$ disagreed that $\mathrm{HBV}$ was an indication for Cesarean section (C-section) (Table 2).

\section{Education and interpretation of HBV serologies}

Half of PDs believed residents from their programs were comfortable in managing HBV in pregnancy, but only $41.8 \%$ of residents reported being comfortable managing these patients (Table 2). Only 23.5\% of training programs have dedicated teaching about HBV in pregnancy. With respect to years of training, the percentage of residents who felt comfortable managing HBV increased with post-graduate year: PGY 1 (22\%), PGY 2 (28\%), PGY 3 (42\%), and PGY 4 (69\%) (Fig. 1). A majority of PDs and residents interpreted HBV serologies correctly (Table 3 ).

\section{Discussion}

Because screening based on risk factors alone will miss many cases of HBV, universal screening for HBV during pregnancy at the first prenatal visit has been recommended by the ACOG and the US Preventative Services Task Force for many years [5]. In our study, all PDs and over 95\% of residents screened for HBV appropriately at the first prenatal visit.

Despite appropriate screening, significant gaps exist in residents' comfort and education in the management 
Table 1 Characteristics of responding PDs and residents

\begin{tabular}{|c|c|c|}
\hline Responders' characteristics & $\%$ PDs & $\%$ Residents \\
\hline \multicolumn{3}{|l|}{ Overall } \\
\hline Survey response rate & 20.4 & 11.0 \\
\hline \multicolumn{3}{|l|}{ Gender } \\
\hline Male & 37.3 & 10.9 \\
\hline Female & 62.7 & 89.1 \\
\hline \multicolumn{3}{|l|}{ Practice type } \\
\hline Community-based medical center & 32 & 27.6 \\
\hline University-affiliated medical center & 62 & 72.4 \\
\hline Group practice & 4 & 0 \\
\hline Other & 2 & 0 \\
\hline \multicolumn{3}{|l|}{ Practice setting } \\
\hline Urban & 88.2 & 93 \\
\hline Rural & 11.8 & 7 \\
\hline \multicolumn{3}{|l|}{ MFM } \\
\hline MFM specialty training & 15.7 & 2.6 \\
\hline \multicolumn{3}{|l|}{ Geographical distribution } \\
\hline New England (CT, MA, ME, NH, RI, VT) & 7.8 & 9.8 \\
\hline Mid-Atlantic (NJ, NY, PA) & 15.7 & 25.8 \\
\hline East North Central (IL, IN, MI, OH, WI) & 25.5 & 20.7 \\
\hline West North Central (IA, KS, MN, MO, ND, NE, SD) & 9.8 & 11.3 \\
\hline Mountain (AZ, CO, ID, MT, NV, NM, UT, WY) & 9.8 & 2.9 \\
\hline Pacific (AK, CA, HI, OR, WA) & 7.8 & 8.7 \\
\hline South Atlantic (DE, DC, FL, GA, MD, NC, SC, VA, WV) & 3.9 & 14.5 \\
\hline East South Central (AL, KY, MS, TN) & 9.8 & 2.5 \\
\hline West South Central (AR, LA, OK, TX) & 9.8 & 3.6 \\
\hline \multicolumn{3}{|l|}{ Trainee year } \\
\hline PGY 1 & & 24.4 \\
\hline PGY 2 & & 26.2 \\
\hline PGY 3 & & 24.7 \\
\hline PGY 4 and beyond & & 24.7 \\
\hline
\end{tabular}

PD, program director; MFM, maternal-fetal medicine; $P G Y$, postgraduate year

of pregnant patients with $\mathrm{HBV}$, though improvement is seen as they progress through years of training. Even in their last year of training, only 69\% of PGY-4 residents felt comfortable managing a pregnant patient with $\mathrm{HBV}$. This may be related to a lack of clinical exposure, with less than half of residents reporting an adequate amount of clinical exposure to HBV patients. In addition, less than a quarter of programs offer a didactic session on HBV. Better educational initiatives could potentially decrease MTCT rates further.

Maternal infection with $\mathrm{HBV}$ is a major cause of MTCT [6]. A recent study found that a maternal HBV DNA level $>1$ million copies $/ \mathrm{mL}$ at delivery is the most important predictor of in utero MTCT and hepatitis B immune globulin prophylaxis failure [7]. The newest guideline from the Society for Maternal-Fetal Medicine recommends third-trimester $\mathrm{HBV}$ viral load testing and antiviral therapy if viral load is $>6-8 \log 10$ ( 1 million to 100 million) copies/mL [8]. In 20122013, the European Association for the Study of the Liver and the United Kingdom's National Institute for Health and Care Excellence have published similar guidelines, recommending treatment in those with HBV viral load >6-7 log 10 (1 million to 10 million) copies $/ \mathrm{mL}[9,10]$.

With respect to the choice of antiviral therapy, the American Association for the Study of Liver Diseases' revised guidelines in 2009 for the treatment of chronic HBV call for tenofovir and entecavir to be first-line agents, with lamivudine no longer a first-line agent as there has been 


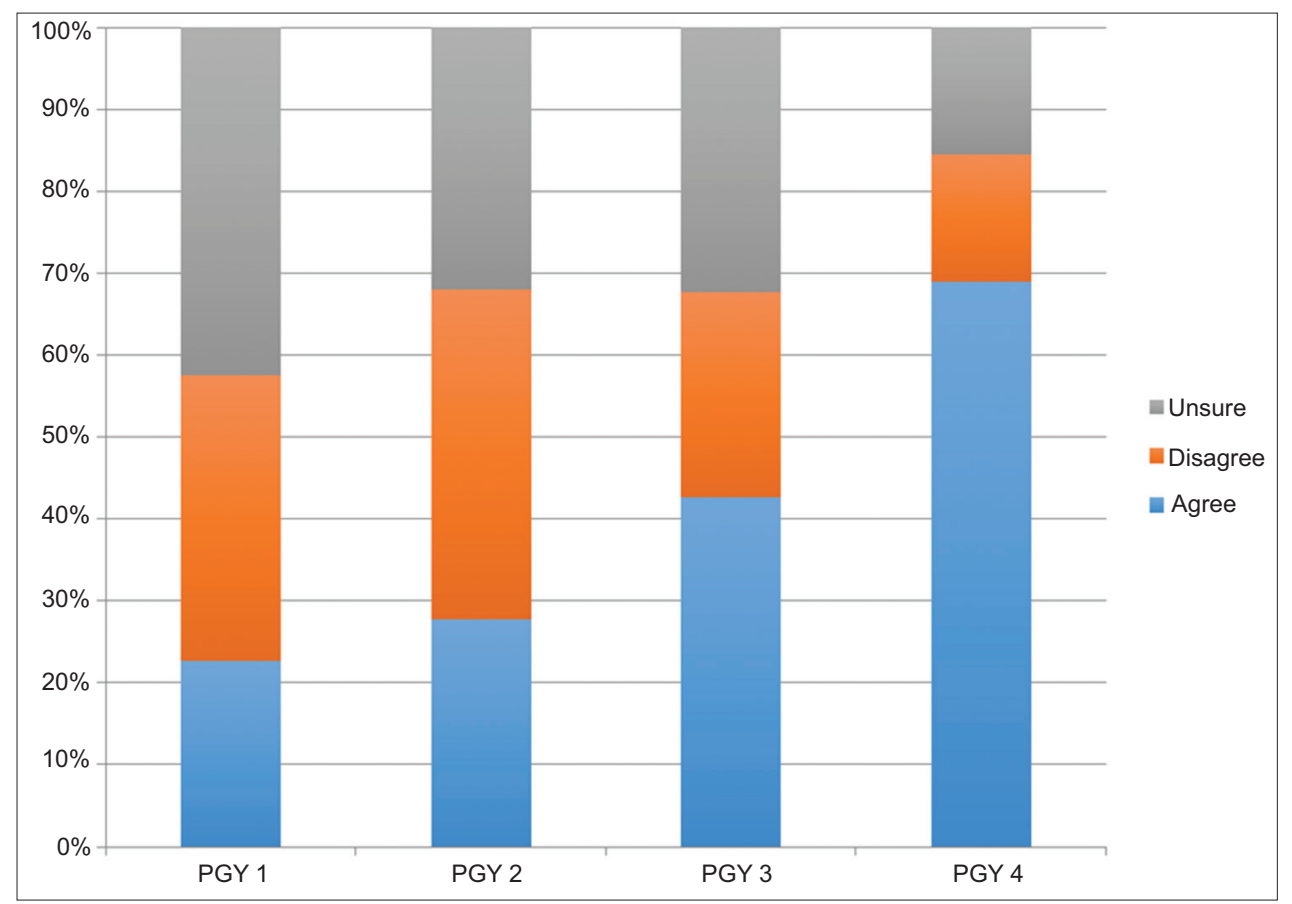

Figure 1 Resident responses to "I feel comfortable managing pregnant patients with chronic hepatitis B" across post-graduate years

Table 2 Summary of selected survey responses from PDs and residents

\begin{tabular}{|c|c|c|c|c|}
\hline Survey questions & Response & $\begin{array}{l}\mathrm{PD} \text { response } \% \\
\quad(\mathrm{n}=51)\end{array}$ & $\begin{array}{l}\text { Resident response \% } \\
\qquad(\mathrm{n}=275)\end{array}$ & $\begin{array}{l}\text { Chi-square } \\
\text { P-value }\end{array}$ \\
\hline \multirow[t]{3}{*}{ C-section is indicated in the setting of maternal HBV } & Agree & 2.0 & 5.1 & 0.018 \\
\hline & Disagree & 98.0 & 83.1 & \\
\hline & Unsure & 0.0 & 11.8 & \\
\hline \multirow{3}{*}{$\begin{array}{l}\text { There is a dedicated teaching session for managing hepatitis B in } \\
\text { pregnancy at my program }\end{array}$} & Agree & 23.5 & 32.5 & $<0.001$ \\
\hline & Disagree & 70.6 & 41.0 & \\
\hline & Unsure & 5.9 & 26.6 & \\
\hline \multirow{3}{*}{$\begin{array}{l}\text { Trainees from my program are comfortable managing a } \\
\text { pregnant patient with hepatitis B }\end{array}$} & Agree & 51.0 & 41.2 & 0.265 \\
\hline & Disagree & 29.4 & 28.7 & \\
\hline & Unsure & 19.6 & 30.1 & \\
\hline \multirow{3}{*}{$\begin{array}{l}\text { The patient population in my program provides adequate } \\
\text { clinical exposure for trainees with regard to HBV in pregnancy }\end{array}$} & Agree & 54.9 & 42.3 & 0.017 \\
\hline & Disagree & 41.2 & 37.5 & \\
\hline & Unsure & 3.9 & 20.2 & \\
\hline
\end{tabular}

PD, program director; $H B V$, hepatitis B virus; C-section, Cesarean section

concern about resistance [11]. Tenofovir has been shown to be associated with no increase in congenital abnormalities or differences in infant growth parameters at birth compared to an untreated control group [12]. The newest guideline from the Society for Maternal-Fetal Medicine recommends tenofovir as a first-line agent in pregnant women who are candidates for antiviral therapy [8]. Interestingly, a majority of PDs who have prescribed antivirals selected lamivudine as their agent of choice, while the majority of residents selected tenofovir. It is likely that the new guidelines have been disseminated faster to those who are currently in training.

Perinatal HBV infection occurs when the infant comes into contact with vaginal blood and secretions during delivery. A Chinese systemic review that included 789 patients showed a significant decrease in vertical transmission associated with elective C-section (10.5\%) compared to vaginal delivery (28.0\%) [13]. However, that review included many studies 
Table 3 Interpretations of HBV serologies

\begin{tabular}{lcc}
\hline Type of HBV serology & \% PD correct & $\begin{array}{c}\text { \% Resident } \\
\text { correct }\end{array}$ \\
\hline Chronic hepatitis B infection & 94 & 86 \\
$\begin{array}{l}\text { Prior infection with hepatitis } \\
\text { B, now resolved }\end{array}$ & 80 & 78.8 \\
$\begin{array}{l}\text { Immune to hepatitis B from } \\
\text { vaccination }\end{array}$ & 82.4 & 90.1 \\
\hline
\end{tabular}

$P D$, program director; $H B V$, hepatitis $B$ virus

\section{Summary Box}

\section{What is already known:}

- Mother-to-child transmission of hepatitis B virus (HBV) occurs when maternal HBV viral load is higher than $1,000,000$ copies $/ \mathrm{mL}$

- Third-trimester initiation of antiviral agents reduces the risk of vertical transmission

\section{What the new findings are:}

- Our survey of all Obstetricians' and Gynecologists' (OB-GYN) residency programs in the United States shows almost all OB-GYNs screen pregnant patients for HBV

- A minority of OB-GYN respondents knew that third trimester antivirals are recommended for women with high viral loads

- Less than half of residents report that they are comfortable managing patients with HBV

- Less than a quarter of residency programs have dedicated teaching about HBV in pregnancy

that did not report maternal HBV DNA viral load. Currently, the OB-GYN literature does not support chronic HBV as an indication for C-section [8]. The majority of PDs and residents in our survey reported similar opinions regarding C-section.

Although we surveyed PDs and residents in the entire US, the major limitations of our study include the recall bias inherent in survey studies and the slightly low response rates. We elected to survey PDs as representative of physicians in practice. However, this may not be accurate, as PDs are perhaps more knowledgeable about changing guidelines than are their non-teaching colleagues.
Overall, despite excellent self-reported screening for hepatitis B in pregnant women, OB-GYN knowledge and education regarding management, especially in patients with higher viral loads during the third trimester, is still lacking. Improvement in education and dissemination of guidelines can further decrease vertical transmission in this vulnerable population.

\section{References}

1. Masters BR. Mandell, Douglas, and Bennett's Principles and Practice of Infectious Diseases, Eighth Edition (2015) Eds: John E. Bennett, Raphael Dolin, Martin J. Blaser. ISBN: 13-978-1-45574801-3, Elsevier Saunders. Graefes Arch Clin Exp Ophthalmol 2016;254:2285-2287.

2. Kubo A, Shlager L, Marks AR, et al. Prevention of vertical transmission of hepatitis B: an observational study. Ann Intern Med 2014; 160:828-835.

3. Din ES, Wasley A, Jacques-Carroll L, Sirotkin B, Wang S. Estimating the number of births to hepatitis B virus-infected women in 22 states, 2006. Pediatr Infect Dis J 2011;30:575-579.

4. Terrault NA, Bzowej NH, Chang KM, Hwang JP, Jonas MM, Murad MH; American Association for the Study of Liver Diseases. AASLD guidelines for treatment of chronic hepatitis B. Hepatology 2016;63:261-283.

5. American College of Obstetricians and Gynecologists. ACOG Practice Bulletin No. 86: Viral hepatitis in pregnancy. Obstet Gynecol 2007;110:941-956.

6. Burk RD, Hwang LY, Ho GY, Shafritz DA, Beasley RP. Outcome of perinatal hepatitis $B$ virus exposure is dependent on maternal virus load. J Infect Dis 1994;170:1418-1423.

7. Pan CQ, Duan ZP, Bhamidimarri KR, et al. An algorithm for risk assessment and intervention of mother to child transmission of hepatitis B virus. Clin Gastroenterol Hepatol 2012;10:452-459.

8. Dionne-Odom J, Tita AT, Silverman NS; Society for MaternalFetal Medicine (SMFM). \#38: Hepatitis B in pregnancy screening, treatment, and prevention of vertical transmission. Am J Obstet Gynecol 2016;214:6-14.

9. European Association For The Study Of The Liver. EASL clinical practice guidelines: Management of chronic hepatitis B virus infection. J Hepatol 2012;57:167-185.

10. National Clinical Guideline Centre (UK). Hepatitis B (Chronic): Diagnosis and management of chronic hepatitis B in children, young people and adults [Internet]. London: National Institute for Health and Care Excellence (UK); 2013 [cited 2016 Dec 16]. Available from: http://www.ncbi.nlm.nih.gov/books/NBK254250

11. Lok AS, McMahon BJ. Chronic hepatitis B: update 2009. Hepatology 2009;50:661-662.

12. Greenup AJ, Tan PK, Nguyen V, et al. Efficacy and safety of tenofovir disoproxil fumarate in pregnancy to prevent perinatal transmission of hepatitis B virus. J Hepatol 2014;61:502-507.

13. Yang J, Zeng XM, Men YL, Zhao LS. Elective caesarean section versus vaginal delivery for preventing mother to child transmission of hepatitis B virus-a systematic review. Virol J 2008;5:100. 